ORIGINAL RESEARCH PAPER

\section{PREDILECTION \& SAFETY OF TRANSRADIAL CORONARY INTERVENTION IN THE ELDERLY POPULATION}

\section{Cardiology}

KEY WORDS: Cag -

Coronary Angiogram, Csa -

Chronic Stable Angina; Acs -

Acute Coronary Syndrome

\section{Mahadevan V}

Jaisankar $\mathbf{P} *$
Assistant Professor,Department Of Cardiology, Chengalpattu Medical College Associate Professor, Department Of Cardiology, Chengalpattu Medical College *Corresponding Author

BACKGROUND: Transradial artery access for coronary intervention procedures is a safe and beneficial techniquel. The safety aspects are well established in young individuals2. Elderly patients have been considered as a higher risk due to increased vascular tortuosity, calcifications and other access site related complications in comparison to younger individuals3. This study was done to assess the feasibility, efficacy and safety of transradial coronary angiography or intervention in the elderly.

MATERIALS \& METHODS: This study was conducted in the department of Cardiology, Chengalpattu Medical College Hospital in patients admitted coronary angiogram either for acute coronary syndrome or chronic stable angina during the period from November 2018 to April 2019. A total of 149 patients who underwent coronary angiography/ intervention through radial artery access were studied. Patients were divided into elderly population with age at or above 65 years $(n=24)$ \& non elderly with age less than $(n=125)$. Most of the patients who underwent procedure in both the groups are for acute coronary syndrome (ACS) than chronic stable angina (CSA), elderly arm (ACS vs. CSA - 91.6\% vs. $8.3 \%$ ) \& non elderly arm (ACS vs.CSA $-90.4 \%$ vs $9.6 \%$ ). The two groups of population were analyzed with respect to complications such as vascular site bleeding, stroke, procedural time \& access site cross over.

RESULTS: The mean age was $72 \pm 3.3$ years in the elderly group and $49 \pm 5.3$ years in the non-elderly group. Baseline serum creatinine values were slightly elevated in elderly arm. The procedural time was higher in elderly arm than non elderly arm both in diagnostic (16 min 20 secs vs. 2 min 45secs) as well as in interventional (4l min 32 secs vs. 19 min 18 secs)procedures. But the volume of contrast utilized is same in both arms with average of $40 \mathrm{ml}$ vs $42 \mathrm{ml}$ in elderly vs. non elderly arm respectively. Occurrence of puncture site bleeding or occlusion of radial artery showed no difference between two arms. The procedure completion was equally safe in both elderly and non elderly group ( $85 \%$ vs.86\%). Access site cross over rate due to vessel tortuosity was higher in elderly arm (8\% vs. $1.5 \%)$ where as vasospasm was less in elderly compared to non elderly group (2.4\% vs $7 \%)$. No case of thrombotic or bleeding risk or stroke were seen in both the arm.

CONCLUSION: Transradial coronary angiography or intervention is safe and complication rates are comparable with those in non elderly patients. Procedural time for the completion of procedure is high in elderly than in non elderly due to tortuous vessel anatomy, difficulty in engaging the coronary artery \& operator efficacy etc.

\section{INTRODUCTION:}

Over the last 2 decades, the uptake of transradial coronary procedures has spreaded across the globe ${ }^{4}$. It has been well documented the beneficial aspects of radial artery access than femoral artery access through large RCT like RIVAL trial ${ }^{5}$, OCTOPLUS ${ }^{6,7}$ study. The primary end point, a composite of vascular complications, transfusion and drop in hemoglobin were significantly lower in the radial group. The radial group had similar contrast volume but longer procedure duration and higher radiation exposure. The access site cross over were similar with $8 \%-9 \%$. National Cardiovascular Data registry form 606 sites in United States between 2004 and 2007 clearly highlighted the lower risk of bleeding complications with radian than femoral access ${ }^{8}$. However this observational data evident the advantage of radial access in patients of aged less than 65 years. Despite the potential benefit of radial access it was inconsistently used less in elderly population. These sentences were echoed in an observational study conducted in United States involving 17509 patients between $2008 \& 2011$ in which elderly patients were less likely to be offered radial access ${ }^{9}$.

\section{MATERIALS \& METHODS}

This is retrospective observation study conducted at Department of Cardiology, Chengalpattu Medical College Hospital from November 2018 to April 2019. Patient who are diagnosed coronary artery disease either acute coronary syndrome or chronic stable angina during the period and underwent diagnostic with or without coronary intervention as per Institute protocol were analysed in this study. The patient population were divided in respect to age with cutoff 65 and above as elderly population and rest as non elderly population. Patient underwent coronary angiogram with Philips cath lab equipments at Cath laboratory, Chengalpattu Medical College Hospital with proper precautions. Serum creatinine was taken in account and estimated glomerular filtration rate was calculated using CKD EPI formula pre and post procedure respectively in both arms. During the procedure at most precaution was taken to reduce the radiation for the patient and operator. The procedure was done through right radial above the styloid process with $5 \mathrm{~F}$ or $6 \mathrm{G}$ hemostatic sheath. Procedural difficulties encountered by various operators were recorded immediately post procedure itself. Quantum of contrast utilized and fluoro time was recorded.

These parameters were analyzed between two arms. $\mathrm{n}=149$;

\begin{tabular}{|l|l|l|}
\hline Parameters & $\begin{array}{l}\text { Elderly arm } \\
(\mathrm{n}-24)\end{array}$ & $\begin{array}{l}\text { Non elderly arm } \\
(\mathrm{n}-125)\end{array}$ \\
\hline $\begin{array}{l}\text { Procedural success } \\
\text { Without complications }\end{array}$ & $85 \%$ & $86 \%$ \\
\hline $\begin{array}{l}\text { Procedural time } \\
\text { a)Diagnostic procedure } \\
\text { b)Interventional } \\
\text { procedure }\end{array}$ & $\begin{array}{l}16 \mathrm{~min} 20 \text { secs } \\
41 \mathrm{~min} 32 \text { secs }\end{array}$ & $\begin{array}{l}2 \text { min } 45 \mathrm{secs} \\
19 \text { min } 18 \text { secs }\end{array}$ \\
\hline Contrast usage & $40 \mathrm{ml}$ & $42 \mathrm{ml}$ \\
\hline Vascular spasm & $33 \%$ & $58 \%$ \\
\hline $\begin{array}{l}\text { Access site cross over } \\
\text { due to vascular spasm }\end{array}$ & $2.4 \%$ & $7 \%$ \\
\hline $\begin{array}{l}\text { Access site cross over } \\
\text { due to Vascular tortuosity }\end{array}$ & $8 \%$ & $1.5 \%$ \\
\hline
\end{tabular}

Submitted : $25^{\text {th }}$ July, 2019

Accepted : $15^{\text {th }}$ September, 2019

Publication : $15^{\text {th }}$ December, 2019 


\begin{tabular}{|l|l|l|}
\hline Bleeding & $<1 \%$ & $<1 \%$ \\
\hline $\begin{array}{l}\text { Difficult in engaging } \\
\text { coronary sinus }\end{array}$ & $28 \%$ & $9 \%$ \\
\hline $\begin{array}{l}\text { Thrombotic occlusion of } \\
\text { radial artery }\end{array}$ & $0 \%$ & $0 \%$ \\
\hline Stroke & $0 \%$ & $0 \%$ \\
\hline Hospital stay & $1-2$ days & $1-2$ days \\
\hline
\end{tabular}

\section{RESULTS:}

The mean age was $72 \pm 3.3$ years in the elderly group and $49 \pm$ 5.3 years in the non-elderly group. Baseline serum creatinine values were slightly elevated in elderly arm with means of 1.15 (mean eGFR 68ml/min) where as in non elderly mean serum creatinine was 1.0 with mean eGFR $94 \mathrm{ml} / \mathrm{min}$ ). The procedural time was measured in terms of fluoro time required to complete the procedure. It was higher in elderly arm than non elderly arm both in diagnostic as well as in interventional procedures.

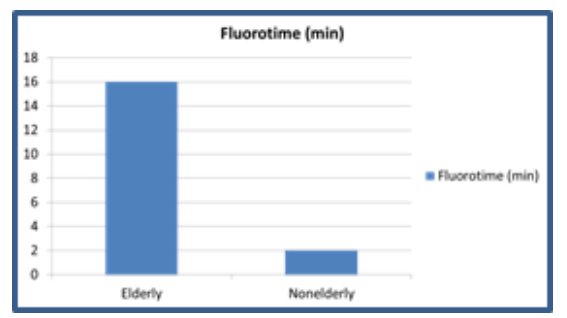

Procedural time and radiation exposure are high due to various reasons such as complex vascular anatomy, learning curve of the operator etc.

\section{REFERENCES:}

1. KobayashiY, Mehran R, Mintz GS et al. Comparison of in-hospital and one year outcomes after multiple coronary arterial stenting in patients above 80 years vs less than 80 years. Am J Cardiol. 2003;92(4):443-446

2. Jolly SS, Amlani S, Hamon M et al .Radial vs femoral access for coronary angiography or intervention and impact onmajor bleeding and ischemic events. Am Heart J 2009; 157(1) 132-140

3. Cao Z, Zhou YJ, et al. Transradial approach for coronary angioplasty in Chinese elderly patients. Chin Med J (Engl) 2008;121:1126-1129

4. Ratib K, Mamas MA, Routledge $\mathrm{C}$ et al. Influence of access site choice on incidence of neurologic complications after percutaneous coronary intervention. Am Hear J.2013;165(3):317-324

5. Jolly SS, Yusuf S, Cairns J et al. Radial versus femoral access for coronary angiography and intervention in patients with acute coronary syndrome. Lancet 2011;377(9775);1409-1420

6. Louvard $\mathrm{Y}$, Benamer $\mathrm{H}$ et al. Comparision of transradial and transfemoral approaches for coronary angiography in octogenarians. Am J Cardiol. 2004;94(9):1177-1180

7. Achenebacj S. Ropers D. T et al . Trans radial versus femoral access for coronary angiography and intervention in patients above 75 years of age Catheter Cardiovasc Interv.2008;72(5):629-635

8. Rao SV.Ou FS, Want TY et al. Tredns in the prevalence and outcomes fo radial and femoral approaches to percutaneous interventions; a report from the National Cardiovascular Data Registry. JACC Cardiovasc Interv. 2008;1(4):379-386

9. Wimmer NJ, Resnic FS, Mauri L et al. Risk Treatment paradox in the selection of transradial access for percutaneous coronary intervention. J Am Heart Assoc. 2013;2(3):e000174

10. McAlister FA. The end of the risk treatment paradox? A rising tide lifts all boats.J Am Coll Cardiol.201 1;58(17):1766-1767

Average fluorotime for diagnostic angiogram in elderly (16 min 20 secs) and in non elderly arm ( 2 min 45 secs) whereas fluorotime for coronary intervention in elderly is $41 \mathrm{~min} 32$ secs \& in non elderly is $19 \mathrm{~min} 18$ secs. Excess procedural times is mainly due to complex vascular anatomy, entering ascending aorta due to excess tortuous of brachiocephalic and difficult engagement of coronary sinus ostium due to dilated aorta.

But the volume of contrast utilized is same in both arms with average of $40 \mathrm{ml}$ vs $42 \mathrm{ml}$ in elderly vs. non elderly arm respectively. Occurance of puncture site bleeding or occlusion of radial artery showed no difference between two arms. More than $85 \%$ patients in elderly arm underwent the procedure safely compared to $86 \%$ in non elderly arm.

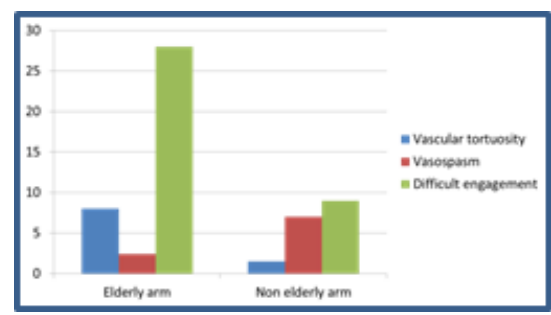

Access site cross over rate was $8 \%$ in elderly arm with major reason is vessel tortuously especially at subclavian and brachiocephalic whereas access site cross over in non elderly was $7 \%$ with major reason is vasospasm. No case of thrombotic occlusion or bleeding risk or stroke seen in both the arms.

\section{SUMIMARY:}

Due to increase in life expectancy, elderly patients undergoing coronary interventions are increasing worldwide. These groups of people are at high risk of both bleeding and ischemic complications. Transradial access for coronary intervention is proved its benefit beyond doubt in reduction of above complications than femoral access ${ }^{10}$. But many RCT cum observations studies shows this benefit in young age population. Radial access is currently very much underutilized in elderly population. From our observation study it is clear that transradial access is beneficial, safe and efficacy in elderly population with minimal complications. 